\title{
Features of Pozzolans in the Robustness and Productivity of the Concrete Constructions
}

\author{
Moein Zargar ${ }^{1}$, Hossein Gholami ${ }^{2}$, Hossein Norouzi ${ }^{3}$, Morteza Soltani ${ }^{4}$, Vijay P. Singh ${ }^{5}$, Mohsen \\ Ghane $^{6^{*},}$, Kaveh Ostad-Ali-Askari ${ }^{2}$ \\ ${ }^{I}$ Department of Civil Engineering, Farzanegan Institute of Higher Education, Isfahan, Iran \\ ${ }^{2}$ Department of Civil Engineering, Isfahan (Khorasgan) Branch, Islamic Azad University, Isfahan, Iran \\ ${ }^{3}$ Department of Civil Engineering, Maybod Branch, Islamic Azad University, Maybod, Yazd, Iran \\ ${ }^{4}$ Department of Architectural Engineering, Shahinshahr Branch, Islamic Azad University, Shahinshahr, Iran \\ ${ }^{5}$ Department of Biological and Agricultural Engineering \& Zachry Department of Civil Engineering, Texas A \\ and M University, 321 Scoates Hall, 2117 TAMU, College Station, Texas 77843-2117, U.S.A. \\ ${ }^{6 *}$ Civil Engineering Department, South Tehran Branch, Islamic Azad University, Tehran, Iran
}

*Corresponding Author: Mohsen Ghane, Civil Engineering Department, South Tehran Branch, Islamic Azad University, Tehran, Iran.

\begin{abstract}
Natural Pozzolans are an incredible basis of responsive silica and alumina needed for geopolymer synthesis as a different binder for normal Portland cement. They are accessible at a relatively low price and create a low ecological footprint through their modest mining. The micro-structural features are depend on the progressive logical methods applied so far to comprehend geo polymerization, the phase configuration, automatic and robustness belongings development. In recent years, 50 percent of the construction budget has been spent on the repair of concrete structures in the industrialized countries. This is also the case in our country, although there is no exact data available. The increasing tendency to understand the causes of concrete deterioration, its prevention, and the factors that increase the strength and resistance of concrete despite its short life of detection indicates the importance of the subject. In the construction of dams, which is an urgent need in our country, the three factors of resistance, impermeability and lifetime are all improved by the use of Pozzolan. For example, if a dam lifetime is supposed to be 50 years, the dam will last for 100 years by using Pozzolan. Use of Pozzolan in hydraulic structures will improve the structure resistance against salt and sulfate including water, getting hot and cold, and high water flow due to its physical and chemical properties.
\end{abstract}

Keywords: Pozzolan, Efficacy, Durability, Impermeability

\section{INTRODUCTION}

Concrete is the most widely used building material in civil engineering projects around the world. There are several reasons among the most important ones are being cost-effective, the availability of sources including concrete ingredient materials, compatibility with the environment and the desirable strength. If the abovementioned factors are considered, appropriate quality of the concrete is obtained. In recent years, more than $50 \%$ of construction budgets have been spent on repairing concrete structures in industrialized countries. Although there are no accurate statistics in this area in our country, the presence of damaged concrete structures, especially in the Persian Gulf border area and the southern coasts, as well as the concrete structures repairs confirms the allocation of large funds in this area. The increasing tendency to understand the causes of concrete deterioration, its prevention, and the factors that increase the strength, durability and resistance of concrete despite its short life of detection (about 125 years) indicates the importance of the subject. Concrete durability is improved by any solution that can eliminate the causes of concrete deterioration [4].

On the other hand, the irregular use of natural materials, production of various products and materials and the increased pollution of environment, production of low quality materials and non-standard constructions, and inadequacy of the structural durability in corrosive environments are among the issues that motivate us to follow the scientific principles governing the durability and efficiency of concrete [4]. From this evaluation is clear that important analytical methods have been positively carried out on new and hardened natural Pozzolan based geo-polymer gained in alkaline medium, 
which assisted to comprehend fundamental chemical response and external features affecting last belongings. These investigates have revealed that usual Pozzolan founded geo-polymer has possible to be applied as maintainable construction resources. But, for its great scale utilization there is essential to upscale the industrial procedure at a pilot-plant in order to report the macroscopic tests that may ascend at that equal. The consequences display that the adding of alumina developed pozzolans advantages the development of hemi Carbo-aluminate that has low density and high filling productivity, which supports to density the matrix. The densified microstructure meaningfully confines the chloride dispersal, and the dispersion deepness can be well showed by the evaporable water content. The mathematical modeling consequences display that the chloride binding clearly retards the chloride dispersal in concrete. In new years, investigators have been concentrating on developing more maintainable cementitious organizations so as to limit the undesirable environmental effects and collapse of concrete structures related with normal Portland cement. Several efforts have been completed to progress maintain able binders through the apply of Pozzolans such as slag, fly ash, palm oil fuel ash, metakaolin, silica fume, rice husk ash etc. with a comparatively larger quantity of additional of ordinary Portland cement. A positive level of cement replacement with those Pozzolans is extremely beneficial in terms of price, energy productivity, ecological and environmental advantages as well as strength possessions. More lately, investigators have mostly depended on the opportunity of applied use of Pozzolans as a part additional of cement in quest for enhanced long-term strength and robustness possessions. By definition, durability is the ability of a structure to maintain the serviceability of each element over a period of time and in a specific environment. The aim of durability studies is to find solutions to increase its lifetime or to protect concrete against the factors that reduce structural strength and performance [4]. Generally, concrete durability is influenced by the environmental (external) factors as well as the internal factors in the concrete itself. From the durability point of view of concrete structures, the environment is divided into different levels. First, the general environment, which is the conditions of the area surrounding the structure. Second, the macro environment at the structure surface, and the micro environment, which is the environment conditions inside the structure or its microscopic section [4]. External factors include physical factors (i. e. successive freezing and melting, changes in temperature and humidity), chemical factors (i. e. sulfate and natural gas attack and steel rust (chlorine attack)), and mechanical factors (i. e. wear, erosion, and vacuum in hydraulic structures) [4]. Internal factors include volumetric changes due to the difference in the thermal properties of rock materials and cement paste, the alkaline reaction of stone grains, and the presence of extra solvents in the concrete ingredients including water, cement, aggregates and additives (material deterioration). Here, some of the above factors are described in detail [4]. Some clays contain alkalis, magnesium, and calcium sulfates, and groundwater that are in contact with such soils will play the role of sulfate Solutionsin practice. Sulfates attack various hydrated cement compounds, especially calcium hydroxide and calcium Hydro-aluminate that are seriously in danger. Upon the reaction of sulfates with these compounds, products such as gypsum are produced, which weaken the surface of concrete, decrease concrete strength and increase the volume of solids by $124 \%$. Another product that is formed by the reaction of sulfates with the calcium Hydroaluminate is calcium Sulfo-aluminate, called "Atryngant", which increases the volume by about 227 percent, resulting in an increase in the volume of concrete and cracking and its fall [4]. As it is known, fresh concrete has alkaline $\mathrm{pH}$ due to the formation of calcium hydroxide and sodium and potassium alkali in cement hydration, and this is a good protection against corrosion of steel used in the concrete. The $\mathrm{pH}$ of the concrete pore water is alkaline and the air $\mathrm{Co} 2$ penetrates into the concrete and converts the calcium hydroxide into calcium carbonate, resulting in a decrease in $\mathrm{PH}$. By a $\mathrm{pH}$ decrease from 10, steel corrosion and deteriorations trarts [4]. In addition to the effects of carbonation, the most important cause of reinforcement rust and corrosion in concrete is the presence of chlorine ion. This phenomenon occurs by the penetration of chlorine ion and the creation of an electrochemical cell with a potential difference between different points in the steel. The formation of rust (ferric oxide) increases the pressure with a tensile stress greater than the concrete tensile stress, the concrete is cracked lost and failed [4]. This kind of concrete failure is related to the interaction of alkali cements and silica of rock materials. In fact, this kind of failure is caused by solution of the existing sodium and potassium hydroxides in the concrete pore water with a silica of aggregates, which exists as active silica in some of the aggregates. This reaction is also the case between the active silica of the aggregates and the existing carbonate and thus, the resulted compound gel is expanded and, by causing stress in concrete, the concrete is cracked [4]. For each of the concrete failures investigated in this paper, there are methods for preventing or reducing destructive effects, but the most reliable method is the use of Pozzolan cements inconstruction of the concrete structures [4]. This type of cement is producedby simultaneous grinding of Pozzolan with clinker, or their separate grinding and subsequent mixing. The Pozzolanic cements are divided into two types of Pozzolanic cements and 
special Pozzolanic cements according to the standards.In Pozzolanic cements, the percentage of Pozzolan is limited to $15 \%$, but in special Pozzolanic cements, the percentage of Pozzolan is between 15 and $40 \%$ [4]. Silica or Aluminate Silica, which is not adhesive alone, but in the form of very fine particles and in the presence of moisture at ordinary temperatures, chemically reacts with calcium hydroxide and produces compounds with cement and adhesion characteristics. Therefore, Pozzolan is a natural or artificial substance that contains active silica. It is necessary for the Pozzolanic material to be in powder form, because only in this case, silica reacts with lime (caused by the hydration of Portland cement)in the presence of water and stable calcium silicates that are adhesive are formed. In general, the common characteristic of all the Pozzolans is their silica being shapeless, or, in other words, being hollow and non-crystalline [4]. From the origin point of view, Pozzolans are divided into natural and synthetic Pozzolans. The natural Pozzolans include diatomaceous earth, Apeline Cherts, Shales, tuffs and volcanic ash. Artificial Pozzolons are product of the metal extraction furnaces and coal-fired power plants [4]. Several concrete properties are improved by the use of Pozzolanic materials, some resulting from the physical properties of Pozzolans, including fine particles and their shape, and the rest resulting from the chemical interaction of Pozzolan with cement [4].

\section{THE IMPROVED PROPERTIES INCLUDE}

A) Reduced concrete permeability, reduced water gain of the mix, improved finishing capability of the concrete and adhesion of the mixand, as a result, improved efficiency of the concrete resulting from the chemical reaction of the Pozzolan with cement.

B) Low hydration temperature, resistance to the simultaneous corrosion of sulfate and chlorine, its suitability in bulk concrete and in tropical regions is among other unique features of Pozzolanic cements. One of the factors affecting the durability of concrete is its permeability.Fine Pozzolanic materials significantly reduce the dimensions of the capillary tubes in the concrete and decrease particles separation and finally, increase its finishing capability. In addition, the fine particles of Pozzolanic materials in concrete reduce water gain of the mixture. All of the above mentioned factors lead to an increase in the efficiency of the concrete, which depends on the degree of adhesion of the concrete mixture, and is improved by using the Pozzolanic materials. However, the hydration temperature of Pozzolanic cements is reduced due to the decrease in the percentage of the effective phases in this process [4]. The simplest justification is that the replacement of the Pozzolan as a part of Portland cement used in the mixture reduces the amount of C3A phase with which the sulfates react with. On the other hand, Pozzolan also reduces the permeability of concrete, and a group of researchers believe that the calcium hydrate silicate gel produced by the interactions between Pozzolan and calcium hydroxide, covers the surface of Alumina as an insulating coating, and increases their resistance to sulfate dissolution. Some others believe that since calcium hydroxide released by the hydration of the phases is absorbed by the active silica of the Pozzolan, and the calcium silicate gel is formed, thus the solution is not lime saturated and, consequently, the solubility of the $\mathrm{C} 3 \mathrm{~A}$ phase is increased and interaction with sulfate occurs in solution phase and no expansion happens. However, the most important is the formation of a calcium hydro silicate cover as a protective of the aluminate phase components against the attack of sulfates. As the main cause of this phenomenon is the chlorine ion penetration in concrete, the best solution to reduce the permeability of concrete is the addition of Pozzolanic materials and their replacement instead of a part of cement in concrete [4]. As it is known, some of the aggregates in the concrete mix may contain active silica that gradually react with the existing alkali in the cement and cause the concrete deterioration. The Pozzolans, due to their fine particles, reduce the penetration of coarse particles of reactive aggregates, and addition of these soft silicon materials decrease the alkaline concentration to as much as low alkaline cements. In fact, they prevent further expansion inside the concrete. In general, Pozzolanic cements increase resistance to chemical attacks of CL ions, Alkali and sulfates. In addition, among the unique characteristics of such cements is the reduction of efflorescence in bulk concrete works and significant reduction in the corrosion of the concrete reinforcements. The most important side or artificial substances include slag, micro-silica, rice husk ash and fly ash. Blast furnace slag is a side product of iron and steel industry and is considered as a material with cement characteristics. Slag is composed of lime, silica, alumina, and a small amount of magnesium oxide and alkaline oxides and iron oxides. As with conventional cement, slag reactivity increases by temperature. Slag softness, like conventional cement, is effective in the reaction, and according to ASTM C989, particles with a particle size greater than 45 micrometers have low activity and thus, the maximum size of slag particles should be limited to 45 micrometers. Typically, slag is grinded as much as the conventional cement. In general, if the slag particles are smaller than 10 to 45 micrometers, they are more effective in age resistance (particles smaller than 45 microns have a softness of 500) [4]. The surface of slag 
particles is smoother than cement, thus improving concrete efficiency. For a constant efficiency, the volume of water can be reduced by 5 to 8 percent, resulting in an increased strength. Slag hydration speed is less than the normal Portland cement. However, the speed of gaining strength of the concrete containing slag is a function of the environment temperature. For example, at $20^{\circ} \mathrm{C}$, the slag concrete strength is less than that of the conventional concrete, but at the age of about 56 days, slag concrete strength may become higher than that of the conventional concrete. At a temperature of $50{ }^{\circ} \mathrm{C}$, the strength of the slag concrete at the age of 3 days is equal to or more than that of the conventional concrete. At the age of 28 days, however, its strength increases substantially in comparison to the conventional concrete. Several properties of concrete are improved by the use of Pozzolan. It prevents the Sulphates and natural gas such as $\mathrm{CO} 2$ attacks and carbonation, chlorine ion attack, which causes corrosion of the reinforcement bar in the reinforced concrete, and the alkaline reaction of aggregates, which all contribute to the corrosion of concrete and deteriorate the durability of concrete. Reduced permeability of concrete, reduced water gain (prevention of capillary effect), improved finishing capability and, as a result, improved performance of concrete results from the fineness and physical properties of Pozzolan. Keep in mind that in hot and dry weather, any type of cement that is used in concrete will crack (reduced strength). The use of Pozzolan in the concrete cement removes this great disadvantage (low hydration heat) [4]. As mentioned, slag is hydrated slower than the conventional Portland cement, which results in a lower hydration temperature. This significantly reduces the temperature of the concrete and in cases with the thermal cracking problem is an advantage. Therefore, in mass concrete, Portland cement type IV can be replaced by the slag. It should be noted, however, that in order to significantly reduce the heat generation of concrete, replacement percent of the cement with slag should be at least 50. Addition of the slag to concrete is very effective against the sulfate attack. In general, the presence of $\mathrm{C} 3 \mathrm{~A}$ and $\mathrm{Ca}(\mathrm{OH})_{2}$ in the slag concrete is much less than that of the conventional concrete, which reduces the damage possibility. It should be considered to replace a significant amount of slag (about 50\%) in concrete to increase the resistance to sulfate. In comparison to the conventional concrete, the reinforcement of the slag concrete is less prone to corrosion and silica-alkaline reaction. This is mainly attributed to decrease in the large pores in the slag concrete, resulting in a decrease in the penetration of water, oxygen, and chlorine, and consequently, a decreased potential for failure due to corrosion and silica-alkaline reaction. Studies also indicated that the existing slag in the concrete has no negative effect on creep, shrinkage and modulus of elasticity [4]. Micro silica is a byproduct of the Ferrosilicon alloy and Silicon metal industry. It is produced in three forms of powder, compacted and slurry. In the form of slurry, it is previously mixed with chemical additives and then added to the concrete mix. To produce compacted silica fume, high pressure is applied to the silica powder. The physical and chemical characteristics of the silica fume are given in Table (1). Generally, silica fume contains $90 \%$ of $\mathrm{SiO} 2$. However, the content of $\mathrm{SiO} 2$ and the degree of its non-uniformity varies depending on the production method. The color of the micro-silica is gray, but is also found in white to black, depending on the content of carbon. Its actual density is 2.1 to 2.2 and its bulk density is 250 to $300 \mathrm{~kg} / \mathrm{m}^{3}$. As mentioned before, the most important characteristic of the micro-silica is the ultra-fine particle size, which is about one percent the size of the Portland cement particles $(0.1$ vs. $10 \mathrm{~m})$ [4]. Because of the ultra-fine particle size of the micro-silica, when mixed with concrete, the viscosity of the concrete is increased and thus, its efficiency is decreased, resulting in a decreased concrete loss. Therefore, the amount of water needed to get certain efficiency is increased. To prevent this phenomenon, a super-plasticizer additive can be used. In other words, the micro-silica cannot be used unless a super-plasticizer is used. The use of micro-silica decreases the concrete particles tendency from being separated. When the amount of micro-silica in concrete is about $10 \%$ higher, particle separation and water grain does not occur, even with a slump loss of 15 to $20 \mathrm{~cm}$. Concrete containing suitable micro-silica has the potential to crack due to plastic shrinkage. Therefore, after concreting, it should be cured in the least possible time with a suitable cover. The generated heat by the micro-silica in concrete depends on the ratio of water to cement and the amount of replacement, and the heat generation of one gram of micro silica in concrete is about 0.3 to 2 times the generated heat of $1 \mathrm{~g}$ of cement. It should be noted that due to the increased strength of concrete due to the use of micro-silica, it is possible to reduce the amount of cement materials in concrete and thus, reduce the total generated heat [4]. Micro-silica is a very active Pozzolan and plays an important role in the gain of strength of concrete even at early ages. Gain of strength in the range of 60 to $80 \mathrm{MPa}$ can easily be achieved for the concrete containing micro silicon, and this strength depends on the type of micro silicon and cement, its amount and curing method. This characteristic is due to the reduction in the volume of large pores, which results in a dense concrete texture and structure. It is well proved that by controlling the quantity and quality of the components of the micro-silicon containing concrete (i. e. gradation, aggregate type and amount of plasticizer additive, etc.), strength of about $200 \mathrm{MPa}$ can be achieved. It should be noted that the temperature of 
the environment and the curing method play a major role in gain of strength of concrete containing micro silicon, particularly at higher temperatures (i. e. $30^{\circ} \mathrm{C}$ ), gain of strength of the micro-silicon containing concrete is faster than the conventional concrete [4]. Micro silicon containing concrete is more resistant to the sulfate attack in comparison to the conventional concrete. The most important reason for this is probably the reduction of calcium hydroxide or lime $(\mathrm{Ca}(\mathrm{OH}))$ in micro-silicon containing concrete, which reduces the formation of gypsum and thus, increases the concrete resistance to sulfate. The chlorine permeability and corrosion of reinforcement in micro silicon containing concrete is less than the conventional concrete. Probably two processes are involved in the behavior of micro silicon containing concrete against corrosion of the reinforcement; reduction of the large pores (greater than $0.1 \mathrm{~m}$ ) as well as decrease in the movement velocity of chlorine ions in the micro-silicon containing concrete. Both of the mentioned processes are very effective in the electrical resistance of the concrete. That's why the electrical resistance of the micro-silicon containing concrete is much higher than the conventional concrete [4]. There are different viewpoints on the effect of micro-silicon on the silica-alkaline reaction. Generally, it can be concluded that the effect of microsilicon on controlling this reaction is a function of the type and the amount of micro-silicon used and its proper distribution in the mixture and the type of active aggregates. There are also controversy viewpoints about the effect of micro silicon on the creep and the modulus of elasticity of concrete, but it can generally be concluded that in the same strengths, concrete containing micro silicon and the conventional concrete show almost the same values of creep and modulus of elasticity.

Table1. Approximate amounts of the slag and micro-silicon (in percent) [4]

\begin{tabular}{|c|c|c|c|}
\hline Chemical composition & Portland type I cement & Slag & Micro silicon \\
\hline $\mathrm{SiO}_{2}$ & 20 & 36 & 90 \\
\hline $\mathrm{AL}_{2} \mathrm{O}_{3}$ & 6 & 9 & $0 / 5$ \\
\hline $\mathrm{Fe}_{2} \mathrm{O}_{3}$ & 3 & 1 & $1 / 2$ \\
\hline $\mathrm{CaO}$ & 64 & 43 & $0 / 2$ \\
\hline $\mathrm{MgO}$ & $1 / 5$ & 7 & $0 / 2$ \\
\hline $\mathrm{Na}_{2} \mathrm{O}-\mathrm{K}_{2} \mathrm{O}$ & 1 & 1 & 2 \\
\hline Loss & 2 & - & 2 \\
\hline
\end{tabular}

Rice husk ash, as its name suggests, is produced by burning the rice husk. Each tone of rice has about 200 kilos of husk, which, after burning, its weight reaches 40 kilos. However, ash can be produced from the burning of other cereal husk. The rice husk contains the highest amount of $\mathrm{SiO}_{2}$ and, when properly burned, can be used as a concrete additive. Like micro-silicon, rice husk ash has suitable Pozzolanic characteristics and has a significant effect on gain of strength and improving the durability of concrete. Chemical composition of the rice husk ash includes $80-95 \%$ of $\mathrm{SiO}_{2}, 1-2 \%$ of $\mathrm{K}_{2} \mathrm{O}$ and 3$18 \%$ of non-burned carbon [4]. Rice husk ash is not only very effective in increasing the strength of concrete, but also plays an important role in increasing the strength of concrete against chloride penetration. Researchers showed that the addition of ash by 15 percent of cement weight to concrete, even with a high water-to-cement ratio (0.7), reduced chlorine penetration considerably. This material is also used in roller concrete. Characteristics of the rice husk ash containing concrete require more research to determine its position in the construction industry. For example, some reports indicated that concrete containing ash has more shrinkage than the conventional concrete, which needs to be further investigated [4]. The usage of calcined clay, in the form of metakaolin, as a Pozzolanic material for mortar and concrete has established substantial consideration in new years. Some countries are wealthy in volcanic zones from which natural Pozzolanic materials can be acquired. Sodium betonies is distinguished as a natural Pozzolan that can amended the mechanical features of cemented materials due to its excellence and high content of silica and alumina. When blended with cement paste in a suitable number, it is efficient to impart Pozzolanic result which is essential to assure maintained stability gain of cemented materials. For consolidation of extremely organic soil such as peat, investigation efforts that goal to measure these effects with sodium bentonite as a natural Pozzolan are fairly rare. Sodium bentonite has created affirmative filler and Pozzolanic outcomes on steadied peat. Creation of a lime-Pozzolan concrete with a 28-day cube strength of nearly $50 \mathrm{MPa}$ and an elastic modulus of $20 \mathrm{GPa}$ has displayed the possibility of generating modern, structural grade hydraulic Lime-Pozzolan concretes. making and experiment of two reinforced Lime-Pozzolan concrete beams have sowed the probability of generating structural elements with a terminated exterior and flexural treatment like to Portland cement concrete. As well as, structure and experiment of two reinforced Lime-Pozzolan concrete beams have shown the probability of generating structural components with an accomplished exterior and flexural treatment like to Portland cement concrete. 
The article reverberates on the assessment of this recent material's technological development in the ground of the industry-wide research for low carbon cement. The persistence of mortar/concrete comprising blended Pozzolans and cement is inspected. A determined level of cement substitution with those Pozzolans is extremely advantageous in terms of cost, energy efficiency, ecological and environmental advantages as well as persistence features. More lately, scholars have mostly concentrated on the probability of feasible use of Pozzolans as partial substitution of cement in the search for amended long-term stability and persistence properties.

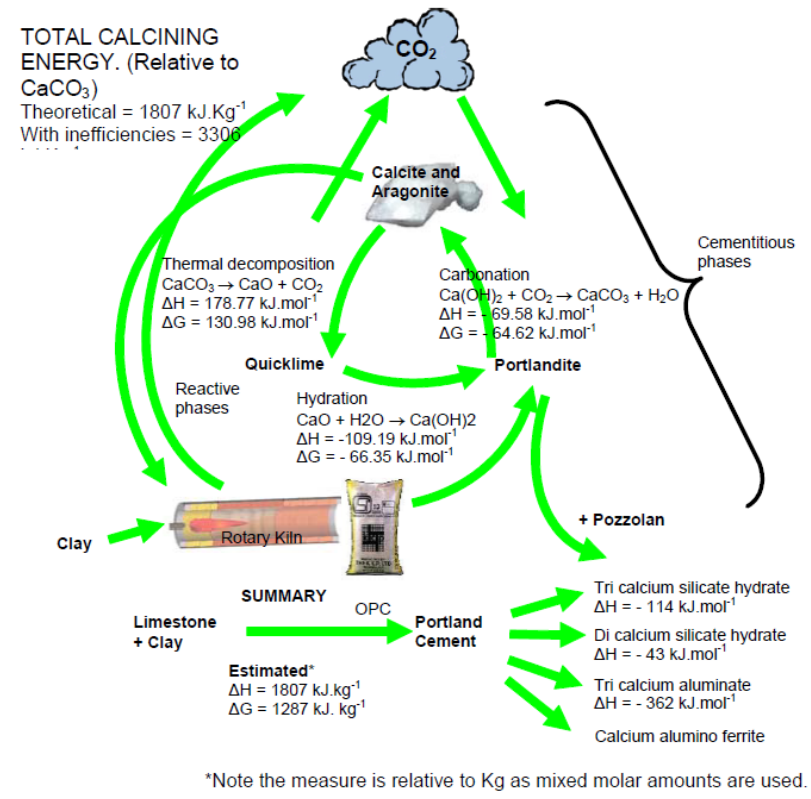

Figure1. The limestone Portland cement System (inefficiencies estimated) [36].

\section{CONCLUSION}

Pozzolans, due to their physical and chemical properties, can be used in hydraulic structures (ports and docks), water reservoirs, dams and canals, and in bulk concretions in hot and dry air. Table 2 shows the reason and cases of using such concretes [4]. The displacement of Portland cement with either complementary cementitious material or fillers, such as natural Pozzolans or limestone powder individually, is recognized to modify the chemical attributes of concrete, thus affecting its new and hardened properties. The persistence of concrete structures and, as a result, their service life, have amended notably due to the initiation of Pozzolans to the industry; thus, using lately expanded Pozzolans has become an urgency for the construction of concrete structures, mainly in aggressive environments. Consequences display that, in common, the zeolite is not as active as silica fume or metakaolin, although it could be applied as a replacement for Pozzolans because it has superior durability features and is inexpensive and environmentally amiable as well. This article deals with the use of efficiency-depend way on the permanence of concrete created with a natural Pozzolan. The consequences of special indexes for erosions and acid attacks displayed that gaining the Pozzolan content led to the superior persistence of the concrete. This article prepares data on apply of coal fly ash as a Pozzolan in concrete. Fly ash can be applied to partly change Portland cement in concrete, and it's applied prepares many practical, financial, and environmental advantages. The features of fly ash and the Pozzolanic response are reported. The effect of fly ash on the features of concrete in the fresh (plastic) and hardened conditions are considered, and specific stress is set on illustrated how to fly ash can affect the long-term permanence of the material. Data is also given on different usages of fly ash. The article also prepares context data on coal bottom ash, and its application in cementitious material, concrete, and other construction usages. Iran is wealthy in volcanic zones from which natural Pozzolanic substances can be acquired. It considers the application of such natural Pozzolans as a sectional replacement of ordinary Portland cement in amplified mortar samples. It was established that the use of Pozzolan has finished in a considerable increment in mortar resistivity and corrosion initiation time for the same cover depth, and as a result, reduces the rate of erosion of rebars once erosion was begun. The enhancement of curing time, as well as the increase of the natural Pozzolan, for both percentages examined, amended the erosion treatment. The mixture of the Pozzolan supplement with longer curing time decreases the steel rebars mass loss up to an external of 
about $40 \%$ after five months of disposal. Pozzolans are substances of the natural or sophisticated source that are not cementitious by themselves but form a hydraulic cement when mixed with lime hydrate owing to their Alumino-siliceous combination. The response of Pozzolan with lime formerly available in cement or released during the hydration procedure improve some features of the cement and the terminating concrete. These articles investigate the possibility of using Pozzolan from a natural origin in many countries as a Pozzolanic material. This Pozzolan is seldom applied in concrete due to the lack of a complete study of its resources. The persistence of concrete structures and, as a result, their service life, have amended notably owing to the preliminary of Pozzolans to the industry; thus, applying lately expanded Pozzolans has become an essential for the construction of concrete structures, mainly in offensive circumferences. the organizations of amorphous silica of Isparta zone are determined in a technical manner and their application in the concrete manufacturing as a natural Pozzolan is evaluated. The efficiency of amorphous silica in creation high strength concrete material is analysed experimentally, and the investigation discoveries are debated. This article reverberates on the value of this recent material's technological improvement in the context of the industry-wide search for low carbon cement. It shows the compressive strength, allowable $\mathrm{CO} 2$, embodied energy and binder severity of hydraulic Lime-Pozzolan concretes, in comparison with those of Portlandcement depend on concretes of equivalent 28-day compressive strength. Generation of a limepozzolan concrete with a 28 -day cube strength of roughly $50 \mathrm{MPa}$ and an elastic modulus of $20 \mathrm{GPa}$ has showed the possibility of generating modern, structural grade hydraulic Lime-Pozzolan concretes. This article examines work carried out on the apply of metakaolin as a sectarian Pozzolanic substitution for cement in mortar and concrete and in the containment of containment garbles.

Table2. Application cases of Pozzolanic cement and their reasons [4]

\begin{tabular}{|c|c|c|}
\hline No. & Application & Reason \\
\hline 1 & Hydraulic structures (docks) & $\begin{array}{l}\text { Resistance to abrasion and cavitations and salt and } \\
\text { sulfates }\end{array}$ \\
\hline 2 & Water reservoirs & Impermeability and prevention of capillary effect \\
\hline 3 & Application in hot and dry weather & Prevention from cracking \\
\hline 4 & Construction of dams & $\begin{array}{l}\text { Due to bulk concreting, large hydration heat } \\
\text { is generated that causes concrete expansion and } \\
\text { cracking, but this is not the case with Pozzolan } \\
\text { containing concrete. } \\
\text { - Strength } \\
\text { - Improves durability and impermeability }\end{array}$ \\
\hline
\end{tabular}

Table3. Pozzolanic activity of various Pozzolans [62]

\begin{tabular}{|c|c|c|c|}
\hline Pozzolan & silica fume & fly ash & metakaolin \\
\hline Reactivity Mg & 427 & 875 & 1050 \\
$\mathrm{Ca}(\mathrm{OH}) 2 / \mathrm{g}$ Pozzolan & & & \\
\hline
\end{tabular}

\section{REFERENCES}

[1] Ramzanian, Ali Akbar, 1997.Additives and Pozzolan and its Application in Concrete, Tehran. Road, housing and urban Development Research Center.

[2] Ramzanian, Ali Akbar, 1998.Cement substitute materials in concrete, Tehran. Road, housing and urban Development Research Center.

[3] Ramzanian, Ali Akbar, 1995.Investigating the researches on the consumption of rice hulls and ash in the construction industry, Tehran, housing and urban Development Research Center.

[4] Kamyab, Mohammad, 2003. The Role of Pozzolans in the Durability and Efficiency of the Concrete Structures. $10^{\text {th }}$ Students Conference on Civil Engineering.

[5] Rafia Firdous, Dietmar Stephan, Jean Noël Yankwa Djobo, 2018. Natural Pozzolan based geo-polymers: A review on mechanical, micro-structural and durability characteristics. Construction and Building Materials, Volume 190, 30 November 2018, Pages 1251-1263.

[6] Yunyao Wang, Zhonghe Shui, et al. 2019. Understanding the chloride binding and diffusion behaviors of marine concrete based on Portland limestone cement-alumina enriched Pozzolans. Construction and Building Materials, Volume 198, 20 February 2019, Pages 207-217.

[7] M. M. Hossain, M. R. Karim, M. Hasan, M. K. Hossain, M. F. M. Zain. Durability of mortar and concrete made up of Pozzolans as a partial replacement of cement: A review. Construction and Building Materials, Volume 116, 30 July 2016, Pages 128-140. 
[8] Mahdi Koushkbaghi, Pedram Alipour, et al. 2019. Influence of different monomer ratios and recycled concrete aggregate on mechanical properties and durability of geo-polymer concretes. Construction and Building Materials, Volume 205, 30 April 2019, Pages 519-528.

[9] Moein Khoshroo, Ali Akbar Shirzadi Javid, Ali Katebi, 2018. Effects of micro-nano bubble water and binary mineral admixtures on the mechanical and durability properties of concrete. Construction and Building Materials, Volume 164, 10 March 2018, Pages 371-385.

[10] Khashayar Ebrahimi, Mohammad Javad Daiezadeh, Mohammad Zakertabrizi, Farhad Zahmatkesh,

[11] Asghar Habibnejad Korayem. A review of the impact of micro- and nano-particles on freezethaw durability of hardened concrete: Mechanism perspective. Construction and Building Materials, Volume 186, 20 October 2018, Pages 1105-1113.

[12] Kemal Celik, Rotana Hay, Craig W. Hargis, Juhyuk Moon. 2019.Effect of volcanic ash pozzolan or limestone replacement on hydration of Portland cement. Construction and Building Materials, Volume 197, 10 February 2019, Pages 803-812.

[13] Mahdi Valipour, Farhad Pargar, Mohammad Shekarchi, Sara Khani, 2013. Comparing a natural pozzolan, zeolite, to metakaolin and silica fume in terms of their effect on the durability characteristics of concrete: A laboratory study. Construction and Building Materials, Volume 41, April 2013, Pages 879-888.

[14] Federica Lollini, Elena Redaelli, Luca Bertolini. 2016. A study on the applicability of the efficiency factor of supplementary cementitious materials to durability properties. Construction and Building Materials, Volume 120, 1 September 2016, Pages 284-292.

[15] Mohammad Balapour, Alireza Joshaghani, Fadi Althoey, 2018. Nano-SiO2 contribution to mechanical, durability, fresh and micro-structural characteristics of concrete: A review. Construction and Building Materials, Volume 181, 30 August 2018, Pages 27-41.

[16] Shukai Cheng, Zhonghe Shui, Tao Sun, Yun Huang, Kaizhi Liu, 2018. Effects of seawater and supplementary cementitious materials on the durability and microstructure of lightweight aggregate concrete. Construction and Building Materials, Volume 190, 30 November 2018,Pages 10811090.

[17] N. Kaid, M. Cyr, S. Julien, H. Khelafi, 2009. Durability of concrete containing a natural Pozzolan as defined by a performance-based approach. Construction and Building Materials, Volume 23, Issue 12, December 2009, Pages 3457-3467.

[18] Yuan-Yuan Chen, Su-Yu Chen, Chien-Jou Yang, Hei-Tao Chen, 2017. Effects of insulation materials on mass concrete with Pozzolans. Construction and Building Materials, Volume 137, 15 April 2017, Pages 261-271.

[19] M. Thomas, R. Jewell, R. Jones, 2017. Coal fly ash as a pozzolan. Coal Combustion Products (CCP's), 2017, Pages 121-154.

[20] R Ramkrishnan, B Abilash,et al. 2018. Effect of Mineral Admixtures on Pervious Concrete. Materials Today: Proceedings, Volume 5, Issue 11, Part 3, 2018, Pages 24014-24023.

[21] Reza Abbaszadeh, Amir Modarres, 2017. Freeze-thaw durability of non-air-entrained roller compacted concrete designed for pavement containing cement kiln dust. Cold Regions Science and Technology, Volume 141, September 2017, Pages 16-27.

[22] Ghasan Fahim Huseien, Kwok Wei Shah, Abdul Rahman Mohd Sam. 2019. Sustainability of nanomaterials based self-healing concrete: An all-inclusive insight. Journal of Building Engineering, Volume 23, May 2019, Pages 155-171.

[23] Harry D. Dennis, Ally J. Evans, Alexander J. Banner, Pippa J. Moore.2018.Reefcrete: Reducing the environmental footprint of concretes for eco-engineering marine structures. Ecological Engineering, Volume 120, September 2018, Pages 668-678.

[24] Christopher Fapohunda, Bolatito Akinbile, Ahmed Shittu, 2017. Structure and properties of mortar and concrete with rice husk ash as partial replacement of ordinary Portland cement - A review. International Journal of Sustainable Built Environment, Volume 6, Issue 2, December 2017, Pages 675-692.

[25] Mahdi Nematzadeh, Saber Fallah-Valukolaee, 2017. Erosion resistance of highstrength concrete containing forta-ferro fibers against sulfuric acid attack with an optimum design Construction and Building Materials, Volume 154, 15 November 2017, Pages 675-686.

[26] Hosam El-Din H. Seleem, Alaa M. Rashad, Basil A. El-Sabbagh, 2010. Durability and strength evaluation of high-performance concrete in marine structures. Construction and Building Materials, Volume 24, Issue 6, June 2010, Pages 878-884.

[27] S. Mahmoud Motahari Karein,, Payam Vosoughi, Soroush Isapour, Moses Karakouzian, 2018. Pretreatment of natural perlite powder by further milling to use as a supplementary cementitious material. Construction and Building Materials, Volume 186, 20 October 2018, Pages 782-789. 
[28] KaizhiLiu, Zhonghe Shui, et al. 2019. Effects of combined expansive agents and supplementary cementitious materials on the mechanical properties, shrinkage and chloride penetration of selfcompacting concrete. Construction and Building Materials, Volume 211, 30 June 2019, Pages 120-129.

[29] K. M. Liew, A. O. Sojobi, L. W. Zhang, 2017. Green concrete: Prospects and challenges. Construction and Building Materials, Volume 156, 15 December 2017, Pages 1063-1095.

[30] G. Fajardo, P. Valdez, J. Pacheco, 2009. Corrosion of steel rebar embedded in natural pozzolan based mortars exposed to chlorides. Construction and Building Materials, Volume 23, Issue 2, February 2009, Pages 768-774.

[31] Arash Aghaeipour, Morteza Madhkhan, 2017. Effect of ground granulated blast furnace slag (GGBFS) on RCCP durability. Construction and Building Materials, Volume 141, 15 June 2017, Pages 533-541.

[32] K. Celik, M. D. Jackson, Et al. 2014. High-volume natural volcanic Pozzolan and limestone powder as partial replacements for Portland cement in self-compacting and sustainable concrete. Cement and Concrete Composites, Volume 45, January 2014, Pages 136-147.

[33] Chao Fan, Sabbie A. Miller. 2018. Reducing greenhouse gas emissions for prescribed concrete compressive strength. Construction and Building Materials, Volume 167, 10 April 2018, Pages 918-928.

[34] M. Cyr, 2013. Influence of supplementary cementitious materials (SCMs) on concrete durability. EcoEfficient Concrete, 2013, Pages 153-197.

[35] Victor C. Li, 2019. High-Performance and Multifunctional Cement-Based Composite MaterialEngineering, In press, accepted manuscript, Available online 9 March 2019.

[36] W Harrison A-J, 2003. New cements based on the addition of reactive magnesia to Portland cement with or without added Pozzolan. BSBE FCPA - Proc.,

[37] Mehta PK. Role of cementitious material in sustainable development of the concrete industry. In: Proceedings of the Sixth CANMET/ACI International Conference on Fly Ash, Silica Fume, Slag and Natural Pozzolans in Concrete, vol. 1, SP-178. Bangkok: V.M. Malhotra; May 1998. p. 1-20

[38] Concrete Society. Changes in the properties of ordinary Portland cement. Technical report 29; 1987. p. 1-30

[39] Stanley CC. The history of concrete. Cement and Concrete Association. Wexham Springs, UK, ISBN 0 72101156 X; 1979. p. 3-9

[40] Mehta PK. Supplementary cementing materials for concrete. V.M. Malhotra, CANMET (Sp-86-8E); 1987. Malinowski R. Concrete and mortar in ancient aqueducts. Concrete Int. 1979:66-76.

[41] Mielenz RC. Mineral admixtures - history and background. Concrete Int. 1983:34-42

[42] F.M Lea .The chemistry of cement (3rd ed.), Arnold, London (1970)

[43] Baronio G, Binda L. Study of the Pozzolan city of some bricks and clays. In: Proceedings of the 10th International Building Materials Conference. Calgary; July 1994. p. 1189-97

[44] Teutonico JM, Mc Caig I, Burns C, Ashhurst J. Factors affecting the properties of lime-based mortars for use in the repair and conservation of historic buildings. English Heritage, The Smeaton Project, Research Project ACI: Phase I Report, Published by English Heritage, Architectural Conservation Branch, Science and Conservation Division, March 1994

[45] Copernicus Research Project. Recycling of waste clay brick and tile material for the partial replacement of cement in concrete. Research contract No. CIPA-CT94-0211, First annual report, 1996, Second annual report, 1997 and Third annual report, 1998

[46] Saad MNA, de Andrade WP, Paulton VA. Properties of mass concrete containing active pozzolan made from clay. Concrete Int July 1982:59-65

[47] G.W Brindley, M Nakahira The kaolinite-mullite reaction series: I, Survey of outstanding problems. J. Am. Ceram. Soc., 42 (7) (1959), pp. 311-314

[48] G.W Brindley, M Nakahira The kaolinite-mullite reaction series: II, Metakolin J. Am. Ceram. Soc., 42 (7) (1959), pp. 314-318.

[49] G.W Brindley, M Nakahira The kaolinite-mullite reaction series: III, High temperature phases.J. Am. Ceram. Soc., 42 (7) (1959), pp. 3319-3324

[50] R.A Sayanam, A.K Kalsotra, S.K Mehta, R.S Sing, G Mandal Studies on thermal transformations and Pozzolanic activities of clay from Jammu region (India) J. Thermal Analysis, 35 (1989), pp. 9-106

[51] J Ambroise, M Murat, J Pera Investigations on synthetic binders obtained by middle-temperature thermal dissociation of clay minerals. Silicates Industries, 7 (8) (1986), pp. 99-107

[52] J Pera, J Ambroise, A Messi Pozzolanic activity of calcined laterite. Silicates Industries, Ceram. Sci. Technol., 63 (7-8) (1998), pp. 107-111 
[53] Malquori G, Portland-Pozzolan cement. In: Proceedings of the Fourth International Symposium on Chemistry of Cement. Washington DC; 1960. p. 983-88

[54] Turrizani R. The chemistry of cement, vol. 2. H.F.W. Taylor; 1964. p. 69-86

[55] P.S De Silva, F.P Glasser Hydration of cements based on metakaolin: thermochemistry. Adv. Cement Chem., 3 (12) (1990), pp. 167-177

[56] A.M Dunster, J.R Parsonage, M.J.K Thomas The pozzolanic reaction of metakaolin and its effects on PC hydration. J. Mater. Sci., 28 (1993), pp. 1345-1350

[57] S Wild, J Khatib, L.J Roose Chemical and autogenous shrinkage of Portland cement-metakaolin pastes. Adv. Cement Res., 10 (3) (1998), pp. 109-119

[58] M Murat Hydration reaction and hardening of calcined clays and related minerals. Cement Concrete Res., 13 (1983), pp. 259-266

[59] J.M Kinuthia, S Wild, B.B Sabir, J Bai Self-compensating autogenous shrinkage in Portland cementmetakaolin-fly ash pastes. Adv. Cement Res., 12 (1) (2000), pp. 35-43

[60] Khatib JM, Sabir BB, Wild S. Some properties of metakaolin paste and mortar. In: Dhir RK, Dyer TD, editors. International Congress, Concrete in the Service of Mankind - Concrete for Environmental Enhancement and Protection, Theme 6 Waste Materials and Alternative Product, University of Dundee, 1996. London: E \& F N Spon; 1996. p. 637-44

[61] Ambroise J, Martin-Calle S, Pera J. Pozzolanic behavior of thermally activated kaolin. In: Malhotra VM, editor. Proceedings of the Fourth International Conference on Fly Ash, SF, Slag and Natural Pozzolans in Concrete, vol. 1. Turkey; 1992; p. 731-41.

[62] Sabir B.B, Wild S, Baj J, 2001. Metakaolin and calcined clays as Pozzolans for concrete: a review. Cement and Concrete Composites. Volume 23, Issue 6, December 2001, Pages 441-454. https://doi.org/10.1016/S0958-9465(00)00092-5.

Citation: Moein Zargar, et.al. "Features of Pozzolans in the Robustness and Productivity of the Concrete Constructions", International Journal of Constructive Research in Civil Engineering, 5(2), pp. 33-42. DOI: http://dx. doi.org/10.20431/2454-8693.0502005

Copyright: (C) 2019 Authors, This is an open-access article distributed under the terms of the Creative Commons Attribution License, which permits unrestricted use, distribution, and reproduction in any medium, provided the original author and source are credited. 